\title{
Striving for Higher University World Rankings: The Role of the Language Centre
}

\author{
Andrea Koblížková ${ }^{1, *}$, David Elvis Leeming ${ }^{2}$ \\ ${ }^{1}$ Language Centre, University of Pardubice, Czech Republic \\ ${ }^{2}$ School of Journalism, Language, and Communication, University of Central Lancashire, UK
}

Copyright $\bigcirc 2016$ by authors, all rights reserved. Authors agree that this article remains permanently open access under the terms of the Creative Commons Attribution License 4.0 International License

\begin{abstract}
There has been a long discussion in academia about crucial competencies of university graduates and factors which particular universities manage to perform better in the prestigious Times Higher Education World University Rankings (THE World University Ranking) or Academic Ranking of World Universities (ARWU, also called Shanghai Ranking) than the others. The role of university language centres (LC) has not been explored in this context, till now. This paper deals with a role of LCs as homes not only to language instruction but also as workplaces through which universities may become more successful institutions in terms of the rankings. A meaningful language policy (LP) is thus closely related to the future development of LCs beyond their current perceived role of a university language centre. This paper gives examples of language policy implementation steps while building on marketing principles for addressing target audience needs and communication. Drawing on the higher education institutions (HEI) priorities in terms of university rankings, the $\mathrm{LCs}^{\prime}$ natural role is to foster university communication culture, conditions for successful internalization and readiness to effectively communicate research results. The process of language policy implementation at the Language Centre of the University of Pardubice may provide an insight into the practice of a middle-size institution and illustrate the workplace emancipation process within an HE institution. Attention will be paid to general EU context as well as to tangible experience, implications of which may go beyond the limited space of one institution.
\end{abstract}

Keywords Language Policy, Language Centre, World University Rankings

\section{Introduction}

\subsection{Language Centre Identity}

Today's cultural fusion has a strong impact on our communication and, therefore, mutual understanding becomes a high priority. Our world has become an immensely interrelated place where cultures meet and merge not only through face-to-face encounters of individual speakers, negotiations within enterprises, exchange of academic discourse, mass media broadcasts and but also through virtual communication of noticeably influential social media.

The inherent need of academia to "publish or perish" calls for a common means of communication in the academic sphere. Such a vehicle can be witnessed in the current use of English, as the lingua franca of today, which enjoys the utmost attention for its capability to transmit scientific information. The English language and communication instruction at HEIs is, in a significant number of cases, provided by units often referred to as language centres (LCs).

The LCs' role as integral parts of higher education institutions is sometimes challenged. In public announcements universities do recognise the importance of English and its instruction, however, their own LCs providing language instruction still frequently need to struggle to receive sufficient financial support and recognition from their university management. At times, vagueness in defining the primary focus of LCs brings about questions regarding educational language policies and securing respective financial resources. Rontu and Tuomi [19] stated that LCs are invariably mostly defined as teaching units as their main tasks and positioned as such within their institutions, usually without any officially stated research targets and obligations. Thus, their role is often seen as a service unit.

LCs have changed tremendously alongside the dramatic transformation of tertiary education across Europe during the past two decades. The transformation has reflected globalization trends and the advent of information and communication technology that has accelerated the pace of globalization itself and has become an instrument of massive global communication [20]. There has never been such an enormous amount of young people able to enter the 
academic educational path. However, naturally, not only students but also their teachers and scholars in this closely interconnected world need to communicate across borders. Thus, the university language setting very much depends on how motivated subject teachers at particular institutions are. Numerous universities, being aware of that their effort and funding invested in communication development are being reflected in international dissemination of their scientific achievements, support both student language instruction and academic staff development. Thus, besides the traditional focus on the university students, many LCs can and do contribute to the language and communication competence development of faculties.

As Rontu and Tuomi [18] claimed, the situation and tasks of language centres vary a great deal amongst the European universities and language studies may constitute an integral part of university degrees or they may have no place at all. Currently, university LCs in Europe have been genuinely seeking their souls while exploring their common values and assets, core competencies, and their potential for rather a long time. Despite this diversity Poljakovič [17] argued it is possible to define common characteristic features. According to him, "the main function of a language centre is to provide language education and training for non-linguistic students, that is, students not studying philology or specialising in literary and linguistic studies". The following are the three types of activity common to all language centres, whatever their name or institutional framework and, however, diverse their missions are [17,1]

- practical language training especially for learners not specialising in languages,

- the use of appropriate technology for language learning,

- research and development in the field of language teaching and learning.

The effort to deepen the LC identity analysis in a European context has intensified since the Wulkow initiative started in 2009 [17] and spurred the LCs self-reflection processes. Another intensifying factor can be seen in the commitment the LCs devoted to the successful introduction of the Common European Framework of Reference for Languages (CEFR) and its dissemination even beyond the European continent. The CEFR scale application has been widespread in LCs practice, being one of the rare proxies to which they can adhere in the multifaceted world of language and communication instruction. Following the adoption of the CEFR, the LCs started to explore a scope of related topics both horizontally and vertically covering issues of assessment and testing methodology, teacher's development, needs analysis and syllabus design, language acquisition, rhetoric, intercultural communication competence, etc. Over the time, there has been a strong feeling in LCs they can valuably contribute to language and communication cultures of their institutions and to the professional development of their faculties.

University faculties, however, do not always share the same viewpoint on the role of languages or English as a lingua franca (ELF), respectively, as the LCs do. The faculties' primary concern rests in research and publication activities in respective fields. For LCs, to get the recognition for their contribution to the university research in terms of its language and communication quality, they would need to formulate clearly their own identity in the first place. The LCs traditionally have taken their exclusive teaching task for granted [18] and such an approach naturally estranges them from full incorporation into academia.

Subsequently, we can list two challenges regarding LCs' contribution to the quality of university research and strive for higher ranking:

- The primary focus on teaching predetermines capacities of the LCs for research and readiness of the LCs' staff to carry out respective research, which may be perceived as a disadvantage in negotiating structural positioning within their own institutions.

- Another challenging issue is related to the lack of practical experience of the LC staff with the research and publication processes as such.

These two challenges are interrelated and work as a vicious circle - without management support and securing relevant finance, the LCs cannot devote their time to research, and without the experience in research, they thus cannot contribute to the cultivation of the research and publications. Intriguingly, the discussions on research often omit the latter symbol of the famous $\mathrm{R} \alpha \mathrm{D}$ abbreviation, which is of the utmost attention for the LCs in the above-described context. The "D", standing for development, should be a crucial part of the LCs work, providing perhaps more apt opportunities for LC quality enhancement and emancipation process than the traditional research concept by itself.

The aim of this paper is to bring attention to potential tools the LCs might employ to turn the situation and present themselves as integral units able to contribute in a valuable fashion to the common pool of interest within academia. Stakeholders of the LCs' activities are, besides the LCs' staff, mostly students and management of the faculties/universities. The situation may vary across European universities, though. In certain cases also, the general public may undertake programmes as many LCs are now encouraged to generate profits. However, still it is not a typical model.

The discourse used to explain motives, procedures and benefits of language instruction should reflect the varied audiences/stakeholders involved. As managements of the faculties are not likely to indulge themselves in the beauty of language for its own sake, bearing in mind their long-term financial accountability for university concepts and budgets, it is advisable to reflect some of the marketing techniques in negotiating the LC's positions inside universities.

Humanities naturally differ in their discourse and utterances from the sciences. If, however, the LCs employ the discourse and the mind-set of marketing, they might enjoy more support for their work from their own universities. From the perspective of university management, 
it is widely regarded that profit is essential. But how is this 'profit' quantified by LCs? It is a difficult question to answer. One way to do this would be to examine how an institution is evaluated internationally, e.g. university rankings. As has been suggested, in the main, LCs are there to support students and faculties in their language development. However their function clearly goes beyond this by being an integral factor as to where a university may be placed in those rankings. Hence a return on "investment" on an LC can be easily defined.

The following case of the University of Pardubice will cast light on the above-mentioned statements.

\section{Case of University of Pardubice}

The University of Pardubice (UPa) is a relatively new Czech university (established for only 65 years). The institution educates about 10, 000 students and consists of seven faculties, the oldest being the Faculty of chemical technology. The prevailing focus of the institution rests in sciences. At such a place, naturally, the language instruction cyclically faces challenges and often is insufficiently incorporated into respective study programmes. The UPa LC has received positive feedback for its work from its students and universities' top management. Faculties, however, sometimes view the LC activities as an unnecessary and troublesome element in their study programme structures. With a certain reservation, they support an idea of credited language courses but do not wish to "waste" too many credits on them, let alone to discuss funding the language instruction. Generally, allocation of credits to languages is a "political issue" requiring numerous negotiations. On such occasions, disputes occur about the appropriate role of the LC within the UPa - is the LC more a service or an academic teaching unit? The faculties generally appreciate LC work and its language teaching, but would love to perceive it as a service department providing language instruction and tailor-made translations with a background desire to economize on it as much as possible. The financial limits then do not provide proper room for further development of staff, courses and establishing research.

"Europeans and their languages", the special Eurobarometer 386 carried out in 2012 (EB77.1) [5] by the European Commission, presents the following findings: "Around nine in ten Europeans (88\%) think that languages other than their mother tongue are useful for personal development. Two-thirds of Europeans (67\%) consider English is one of the two most useful languages, and less than one in five mention German (17\%), French (16\%) and Spanish (14\%). A much smaller proportion is Chinese $(6 \%)$, Italian (5\%) and Russian (4\%). There has been a decrease since 2005 in the proportion of Europeans thinking that French and German are important ( -9 percentage points and -5 points respectively) and an increase in the proportion believing that Chinese is an important language ( +4 points).
More than three-quarters (77\%) of respondents think that improving language skills should be a policy priority, with a third (33\%) stating they 'totally agree', reflecting the widespread support for multilingualism."

The LC felt the need to modify and has recently adjusted the university language instruction aims. In compliance with the above-mentioned Eurobarometer 386, the newly phrased LC objectives reflect current trends in terms of foreign language acquisition and multilingualism, intercultural competencies and functional literacy enhancement, languages for academic purposes and field-specific language support. The new language policy of the LC, set in 2012, encompasses language, communication and culture.

The LC delivers teaching of general languages, languages for specific purposes, English for academic purposes, intercultural communication and specific language skills to a great variety of students and staff. However, the focus of the LC comprises also of research in methodology and language pragmatics, and development of numerous projects. The LC does not see itself as a mere supplier of the contracted language courses, neither is it seen as such by the management of the university. In 2011, the positioning of the LC workplace, as well as the commitment to the development of a culture which recognises the importance of quality and intercultural understanding, was set as a process to be undertaken.

The LC's strategy was to clearly define where the key interests of the faculties and the LC overlap and, in conclusion, identify the ways the LC may contribute to the development of the faculties and the university.

The LC's aims and vision did not easily sit within the primary compliance and expectations of the faculties. To harmonize these views, two alternatives were considered: "shall we persuade the faculties about what the language teachers see as an indisputable benefit ("educating the whole person") by promoting the pedagogic viewpoint on languages or shall we opt for the marketing approach and meet the needs, wishes, aspirations of the faculties where they overlap with the ones of the LC?" Kotler [13] stated promotion cannot be effective unless it catches people's attention. However, today, we face a deluge with print, broadcast, and electronic information through billions of Web pages; society have developed ways to protect themselves from information overload. Thus, persuading stakeholders in complex processes of the university environments may be perceived as either slightly aggressive or at least partly overwhelming toward particular faculties. Either way, persuasion may consume a very long time and might be seen to a certain degree as manipulative.

The LC opted for the marketing inspired approach to communication. The marketing approach opens a new common space for both the language experts and all other stakeholders, whose wishes, needs and aspirations are to be reflected in setting language policies at academia. To identify these needs, numerous sources may be addressed, such as Bologna Declaration [2] and the follow-up processes, European Association for Quality Assurance in Higher 
Education Guidelines [3, 7], European Higher Education Area Declaration [4] internal quality assurance procedures, and, last but not least, the European Commission recent project Horizon 2020 [8].

To complement this top-down needs identification, there should be a bottom-up approach in place as well. Every university identifies its own priorities based on needs analyses carried out among its students, graduates, faculties, cooperating companies and labour market conditions in the respective field of study. In any project management process, a need should justify a set objective. Thus, the third element to be reflected in the aim setting process is external, complex information on university ranking and its indicators, which can serve as a source of unbiased information.

There are numerous resources of this nature with complex methodologies for respective fields in place, such as Times Higher Education World University Rankings (THE World University Ranking), Academic Ranking of World Universities (ARWU), QS Ranking, Performance Ranking of Scientific Papers for World Universities (Higher Education Evaluation and Accreditation Council of Taiwan), Ranking Web of World Universities (Cybermetrics Lab (CCHS), a unit of the Spanish National Research Council (CSIC)), CHE-Excellence Ranking (Center for Higher Education), UTD Top 100 Business School Research Rankings (The UT Dallas' School of Management).

In compliance with the current trends of internationalization, which the UPa subscribes to, the LC set its aims and methods which may contribute as the university strives for a higher ranking. As the research indicators and publication impact factors often dominate in the discourse of the faculties over all other quality assessment criteria, the effort of the LC UPa was to clearly identify areas where the LC can help to meet these priorities of the faculties and simultaneously meet the pedagogic language aims.

\section{Role of English at Academia}

To provoke a debate on the role of languages and the $\mathrm{LC}$ at $\mathrm{UPa}$, the LC raised the following questions within the university environment and presented them at university meetings:

\subsection{Can We Research and Publish without Sources in English?}

Scientific results should be shared openly and in such a way that the methods used are capable of being replicated. Publication in a reputable journal implies that reported findings are capable of passing potential testing. Therefore, the ultimate aim of a researcher is to publish in a language up to a standard of an impacted journal, which in an international academic community is English. The impact of a scientific paper is measured by the impact factor (an average number of citations received per paper published in the respective academic journal during the two preceding years), which is frequently used as a proxy for the relative importance of a journal within its field. Therefore, a primary concern of novice scientists is to get published in a reputable journal, to submit grant proposals, produce reports and reviews in English. In this respect, the LC, within its LAP modules, provides expertise in academic writing, academic presentations and intercultural communication for academic international settings and addresses the genuine need of faculties, primarily catering for doctoral student programmes and staff development.

The headline question addressed English communicative competence of researchers. The answer to this question in the current international state of affairs in academia is self-evident. However, the faculty decision-makers lacked detailed information on the way language communicative competence is assessed and at times, they assumed the competencies of faculties and students matched the desired aims. As a follow-up, the faculty management was provided information on students' communicative competence analysis together with explanations of the essential CEFR principles. The discussion resulted in an undisputable picture manifesting a cause and effect process of the ability to get access to the state-of-the-art scientific results and respective language competence making it possible.

\subsection{Can We Make International Students Believe the UPa is the Right Place to Study at without Creating a Friendly Bilingual Environment?}

The European Higher Education Area (EHEA) was launched in 2010 as a common space for students and researchers, as well as to foster vibrant intellectual and academic achievements and to recognize mutually parts of studied programmes within EHEA by the respective Higher Education (HE) institutions. As stated in Standards and Guidelines for Quality Assurance in the European Higher Education Area in 2009 [7] in "the realisation of the EHEA depends crucially on a commitment at all levels of an institution to ensuring that its programmes have clear and explicit intended outcomes; that its staff are ready, willing and able to provide teaching and learner support that will help its students achieve those outcomes; and that there is full, timely and tangible recognition of the contribution to its work by those of its staff who demonstrate particular excellence, expertise and dedication. All higher education institutions should aspire to improve and enhance the education they offer their students."

These EHEA principles together with the outcomes of the Bologna process introducing the European Credit Transfer and Accumulation System (ECTS), adoption of comparable degrees through implementation of the Diploma Supplement, and promotion of international employability lead clearly to internationalisation as a phenomenon present at all HE institutions wishing to keep up to the standards of the EHEA.

Teichler [22] argued that the term "internationalisation" is not employed to depict merely a gradual change or policies aiming for the gradual change in higher education. He claims 
the conceptual divide between an internationally oriented university at the apex of the system, a national university at an intermediate level and a regional university on a more moderate level is obsolete, and all higher education institutions have to be simultaneously international, national and possibly local.

Consequently, we may claim all students should enjoy an equal opportunity to study in the EHEA scheme with adequate support and in an intellectually rich environment. Not providing them with instruction and support in English, besides Czech, which is not widely spoken in either Europe, or beyond, would mean building obstacles to the internationalisation principles. Understandably enough, subject provision should be mediated at such a level of English that would not impair the quality of the content; otherwise, it would strongly contradict the EHEA Guidelines.

Therefore, if the UPa subscribes to the documents mentioned above and refers to them in study organisation areas, it is inevitable to apply the respective operating principles to communication and language policy of the university so as not to suspend international students from participation in their studies.

\subsection{Can we learn English without operating in English?}

UPa students may have two to four lessons of English a week, which amounts to either 26 or 52 hours a term, respectively. The minimum CEFR competence level in 2016, which must be completed by an undergraduate student (within 3 years), is set to B1. For a graduate student, the minimum target level is set to $\mathrm{B} 2$, and a postgraduate student is expected to reach C1. At the same time, the lowest English course opens at $\mathrm{A} 2$ level. Bearing in mind the time allotted to the language instruction per term (mostly 26 hours), it is obvious that achieving the above mentioned levels by undergraduate, graduate and postgraduate students requires a far more generous learning time than the one provided. Thus, the time allotted to language education at UPa does not seem sufficient. Students at higher levels exposed to real-life conversations, e.g. in video-conference lessons, lack self-confidence in communication, seem passive and remain rather unprepared to back their own viewpoints.

In compliance with the previously described reluctance of faculties to assign more credits and time to language courses, the conditions do not favour the students who wish to practice the language and become proficient in higher level interactions in English such as critical and analytical argumentation. Due to these limitations, it can be argued that the introduction of English-mediated subjects would significantly advance the readiness of graduates to operate independently and in a self-confident manner in the labour market.

There are, though, some negative opinions on English-mediated instruction together with a complete immersion into English, e.g. from Asian or African countries. As Santhiram and Tan [20] stated, "the manner in which
English is introduced or re-introduced in the Malaysian educational system does not augur well for the nation-building process as it has created a dual system of instruction which has ramifications on inter-ethnic relations." Obviously, it is seen as a potential danger where nation identity processes have created another layer of social stratification.

On the contrary, countries of the former Eastern bloc went through the experience of international isolation and thus the populations tend to be rather homogeneous, with international communication limited impact on their readiness to use English. The Czech Republic situation reflects this development, and therefore, an opportunity to extend the direct exposure of students to English through creating a bilingual study and work environment gives an added value and intensifies the language instruction as such. So far, no explicit concerns in terms of an endangered national identity or ramifications of the society by an introduction of English into the Czech educational system have been formulated. The scarcity of English-mediated subjects taught is, firstly, caused by lack of teachers capable of instructing in English at the desired level, secondly, by a concern that the form (a foreign language) would impair students' comprehension of the subject content itself.

This situation may raise a secondary question concerning the use of ELF in hands of subject teachers and its relevance for being considered a useful tool for language training.

The professional discourse calls for a precise terminological use in scientific writing of the respective field (English for Specific Purposes, ESP), and the oral communication according to Seidlehofer [21] tends to use ELF linguistic manifestations, in which consistent linguistic norms of English as a foreign language (EFL) are not entirely obeyed. Jenkins, Cogo and Dewey [10] emphasized that the major characteristic of ELF communication is mutual cooperation, along with a strong orientation towards securing mutual understanding regardless the "correctness", for example by employing "let it pass" and "making it normal" strategies. Much of the research that followed the earlier studies of Firth [6] and House [9] have focused on miscommunication and the negotiation and resolution of non-understanding among non-native speakers. Pitzl [16] stated that there is a high degree of interactional and pragmatic competence in the way the non-native speakers signal non-understanding so as not to disrupt the flow of the exchange and yet provide enough information to the interlocutor for the problem to be resolved. Besides the speaking strategies the language users decide to employ to avert problems in understanding in specific professional contexts, there is also a need to develop strategies for maintaining understanding and mutual intelligibility. Lichtkoppler [14], presented examples of the strategies, namely repetition, and Mauranen [15] gave examples of proactive strategies as a clarification, self-repair and repetition paraphrasing in specific situational contexts, such as prolonged silences, minimal response or overlapping talk, as described in detail in Kaur [11]. As Koblizkova claimed, 
sometimes the speakers creatively build new idioms, which then become markers of in-group membership and coin new phrases in the "tolerant" ELF [12].

To conclude, ELF and EFL, including ESP, are complementary and as such should be presented to the faculties - general English taught by language teachers is rather a presumption and "lubricant" of a fluid specific communication. Effective learning embraces not only access to language courses but also exposure to "a real problem" communication through ESP and EAP, to enhance the readiness to disseminate research results.

\section{Role of Rankings}

Scholars and decision makers at faculties see university rankings as a significant proxy for their own accomplishments, according to which they also set the top-down formulated aims, it is of utmost attention for the language specialists and language policy makers to get acquainted with them and deduce respective conclusions for language education and LC positioning strategies. The most frequently cited ranking platforms are Times Higher Education World University Rankings (THE World University Ranking), Academic Ranking of World Universities (ARWU, also called Shangai Ranking), and QS World University Ranking, each of them prioritizing different performance criteria. For the purpose of this article the methodology of the Times Higher Education World University Rankings [23] will be dealt with in more detail.

\subsection{Subject Rankings Methodology}

The THE World University Ranking presents itself as a list of the best global universities and the only international university performance tables to judge world-class universities across all of their core missions - teaching, research, knowledge transfer and international outlook. This description is to be taken with a certain reservation, though, as most of the above-listed rankings present themselves as the most respected, reputable, and recognized rankings in the world. This article does not judge the face-validity of all these rankings; neither does it study their mutual compliance in detail. The minor divergence in the rankings occurs due to their different methodologies. However, their undeniable value rests in the methodology transparency, wide access to academia and education stakeholders to the publicized data, and in the inherent wish of the HE institutions to rank as high as possible in this source of broad comparative performance information.

\subsection{THE World University Ranking}

The THE World University Ranking is, without doubt, one of the most respected HE rankings in the world. Its reputation is, a despite noticeably rising impact of Asian rankings, still very strong. To a degree, its impact might also rest in a traditional Anglo-Saxon view on the HE area and its perceived prestige might be potentiated by the applied invitation-only academic reputation survey principles. This "exclusivity", however, may soon be faced with the unquestionable growth of the Asian universities' performance, and, thus, a rise of publications in other languages, in other cultural formats may be witnessed on a not-too-distant horizon. So far, however, the prevailing dominance of ELF qualifies the THE World University Ranking as a reliable proxy. The reservations may appear, though, when it comes to normalisation of universities' performances against their funding sources. In spite of this very just ambition, it is certainly understandable that the state-of-art performances are difficult to achieve at institutions with a very tight access to funding.

\subsection{THE World University Ranking Methodology}

The THE World University Ranking comprises of 13 calibrated performance indicators grouped into 5 categories as follows:

- Teaching: the learning environment (worth 30 percent of the overall ranking score)

- Research: volume, income and reputation (worth 30 per cent)

- Citations: research influence (worth 30 per cent)

- Industry income: innovation (worth 2.5 per cent)

- International outlook: staff, students and research (worth 7.5 per cent).

As the methodology of the THE World University Ranking states, universities are excluded from the Times Higher Education World University Rankings if they do not teach undergraduates; if they teach only a single narrow subject; or if their research output amounted to fewer than 1,000 articles between 2008 and 2012 (200 a year). On an exceptional basis, institutions that are below the 200-paper threshold are included if they have a particular focus on disciplines with generally low publication volumes, such as engineering or the arts and humanities.

The system is based on scores of performance indicators and all of them with the exception of academic reputation survey subject to "Z-scores" calculations to avert distortions caused by neglecting the researched data nature. The Z-score (sometimes referred to as standard score) calculation standardises different data types on a common scale and enables combining diverse information into a single ranking. The applied methodology makes fair comparisons feasible, relying on dimensionless quantities of the normal distribution. This principle presents information on a number of standard deviations of the observation/datum/information from the mean. A positive standard score indicates a datum above the mean; while a negative standard score places a datum below the mean. As the THE World University Ranking methodology states "each data point is given a score based on its distance from the mean average of the entire data set, where the scale is the standard deviation of the data set. 
The Z-score is then turned into a "cumulative probability score" to arrive at the final totals.

"If University X has a cumulative probability score of 98 , for example, then a random institution from the same data distribution will fall below the institution 98 percent of the time"[23]. For the results of this indicator, the data is highly skewed in favour of a small number of institutions at the top of the rankings. To eliminate the distortion of the overall performance, the THE World University Ranking states an exponential component was added to increase differentiation between institutions ranked lower down the scale. The information collected on a reputation of a university is based on the 10,000-plus responses to annual academic reputation survey of the THE World University Ranking.

\subsection{Key interest areas of The World University Ranking for LCs}

LCs need to identify the key areas of interest where language specialists may contribute, with their insight and expertise, to the university and faculties core ambitions. The methodology of the THE World University Ranking provides information on the structure of the overall performance criteria. All of the above-stated criteria of teaching, research, citations, industry income, and international outlook do not, obviously, provide equal opportunities for enhancing collaboration between scholars and language specialists. A closer perusal is necessary to analyse the promising areas.

\subsubsection{Category of teaching}

The teaching category covers 5 indicators designed to provide a thorough overview of the teaching and learning environment. The collected data exploit results of the invitation-only academic reputation survey (a) run by Thomson Reuters and amounting up to 10,000 responses on the perceived prestige of institutions in both research and teaching. The teaching and learning category comprises also information on (b) a staff-to-student ratio as a simple proxy for teaching quality. The lower the ratio scores, the higher personal attention is likely to be paid to an individual student. Another indicator provides information on (c) the ratio of doctoral to bachelor degrees, and logically the overall score favours institutions where a higher ratio is achieved as a marker of a research-led and knowledge-intensive teaching environment. The number of doctorates awarded by institutions scaled against the number of academic staff (d) provides the fourth indicator while reflecting fairly the different volume of doctoral awards in different disciplines. In response to the strive for fair competition, the fifth indicator (e) is the amount of institutional income scaled against the number of academic staff, which assures purchasing-power parity will not impede participation of any nation in the THE World University Ranking. This is, however, rather a questionable tool, which probably cannot fully reflect the staff potential.

Though the LCs work within the HE institutions is often associated solely with teaching as such, unfortunately, the category break-up makes evident the LCs cannot contribute to all teaching performance indicators to a substantial degree. Their participation is limited to the following areas: firstly, decisions made on numbers of students in language courses scaled against their number of staff, which addresses the aspect of the personal nurturing of an individual student; secondly, LCs staff development leading to doctoral degrees; and thirdly, active approach to income generation through grants, or as the case may be, commercial activities which are debatable, though.

\subsubsection{Category of research}

The research category is constituted by three indicators. The most prominent one is based on (f) university's reputation for research excellence collected from the university peers, involving the 10,000-plus responses to the annual academic reputation survey. Another indicator $(\mathrm{g})$ casts light on university research income, which is scaled to staff numbers and normalised for purchasing-power parity and also takes account of each university's distinct subject profile (sciences, arts and humanities). The research category also includes a measure of research productivity (h). The research output is scaled against the respective number of staff. Papers published in the academic journals indexed by Thomson Reuters per academic, scaled for a university's total size and also normalised for a subject are considered and report thus on an institution's ability to get papers published in impacted journals.

Taking into account the universities scoring highest in the THE World University Ranking, the first twenty universities in the world are in North America (fourteen universities), three UK universities, two Japanese universities and one university from continental Europe. Obviously, the language of impacted journals and of research platforms is clearly English. Hence having a high proficiency of English cannot be underestimated.

To conclude, LCs' contribution to the research category is legitimate. Either the LCs may qualify by publishing in reputable journals (which is, however, questionable in regard to their teaching workloads) or they may assist with augmenting the communication quality of the research results created by their institution.

\subsubsection{Category of citations}

The citations category depicts research influence of a particular institution. It is the most valued indicator, as the THE World University Ranking pronounce it, a flagship, since it truly reflects a potential of an institution to disseminate new knowledge and ideas. The indicator (i) demonstrates research influence by giving it a number of times a published work is cited by scholars globally. According to Thomson Reuters in 2014, more than 50 million citations to 6 million journal articles, published over five years, were examined. The data is drawn from the 12,000 academic journals indexed by Thomson Reuters Web of Science database and include all indexed journals 
published between 2008 and 2012. Furthermore, citations to these papers made in the six years from 2008 to 2013 were also collected. The indicator shows excellent research outcomes and the degree to which a particular institution contributes to the global knowledge. The methodology assures the citation volume is fully normalised and institutions with traditionally high citation counts are not undeservedly favoured.

Drawing on the previously stated expertise of LCs in teaching communication for an academic setting, it is for them of the utmost priority to cater for both students' and novice academics' needs and reflect academic writing and delivering conference papers through English duly in LCs' course structures.

\subsubsection{Category of industry income}

The industry income category, due to its very specific nature, is more and more valued. The category (j) captures income earned by universities from industry through knowledge transfer of the former to the latter. However, this category does not represent a niche where LCs can largely contribute.

An opportunity might rest in developing language competence of researchers as well as in provision of expertise in translation. Such assistance increases the university readiness to gain contracts in the knowledge and technology transfer area, addressing thus more effectively companies requiring English as a medium.

\subsubsection{Category of international outlook}

The international outlook category examines the degree of international collaboration of academic institutions. Its first indicator $(\mathrm{k})$ looks at the degree academics collaborate with international colleagues on research projects and states the information on the ratio of international and domestic academic staff. Another indicator (1) provides information on the degree of attractiveness of the particular university for undergraduates and postgraduates, featuring the ratio of international and domestic students. The higher the ratio scores, the more successful the institution is in luring the intellectual inflow of students from international education market. The third indicator (m) gives information on international co-authorship and calculates the proportion of a university's total research journal publications having the minimum of one international co-author and rewarding higher volumes.

The LCs may obviously contribute to the structure of the international outlook category, either by means of support to or by active participation in the international co-authorship or, as the case may be, by providing quality teaching in language courses for receiving positive, student-return stimulating feedback. LCs' contribution may also rest in language development of academics who deliver English-mediated instruction.

Academic teaching excellence can be addressed as an offer of LCs towards faculties in terms of face-to-face consultancy, tailor-made courses, tutoring etc. These forms of support may be provided to prospective young researchers or ones in need to enhance their readiness for instruction and research activities in English. As it is obviously a sensitive issue, a gradual approach would be wise. Another possibility is a partnership-based system of academic teaching excellence development may be applied through Content and Language Integrated Learning, where a language teacher and a subject teacher meet to work on mutual enrichment.

\section{University of Pardubice Case Study- Reflections}

The University of Pardubice has ambitious plans to compete within the international educational market. Both the research and teaching commitment may be either fostered by respective government financial positive interventions or, vice versa, inhibited by a lack of funding. It is worth mentioning, the total $\mathrm{R} \& \mathrm{D}$ expenditures in the Czech Republic were \$3.54 billion which compares with the annual operating budget of the Harvard University, according to the Thomson Reuters annual institutional reports from 2001 - 2005. Nevertheless, the education market has changed its long-term horizon, thus setting the trends and objectives and putting adequate strategies in place, together with the ones already underway, to achieve them is crucial. The rankings are not perceived only as comparisons of institutions or a proxy, but they help identify good practice and set trends.

\subsection{Reflections on Strategy and Mission}

The careful analysis of the current situation of students and staff competencies, complemented with pursuing the language education trends and interdisciplinary techniques of educational marketing resulted in phrasing the following priorities, stipulated in the $\mathrm{LC}^{\prime}$ 's mission:

- facilitate conditions in which university graduates are able to efficiently and appropriately communicate their interests to their counterparts in the international context

- contribute to the cultivation of institutional communication, development of critical and analytical communication competencies in a foreign language, primarily within ESP and EAP (English for academic purposes)

- raise awareness in intercultural communication issues and rhetoric features of quality presentations and publications

- support students to become self-confident in communication both in professional and social areas bearing in mind language pragmatics

- enhance internationalisation through plurilingual trends 


\subsection{Reflections on Operational Management}

To assure the practical fulfilment of the above-pronounced mission statements, the LC UPa introduced the following activities and secured project funding for them:

- support of communicative competence of university staff (regular long-term organization of seminars, renowned guest lectures, workshops for more than 140 academics over 2013 - 2015)

- support of specific skills development of university staff (organization of specific training in intercultural areas, the methodology of English-mediated teaching over 2013 - 2015)

- international language exams preparatory courses and organization of testing sessions for university staff and students

- tutorials and specialized courses for postgraduate students (ESP, EAP, specific communication skills)

- organization of simulated conferences for Ph.D. students, MA and BA students

- Erasmus testing unified format

- support for a bilingual environment (translations, glossaries, etc.)

The LC has accomplished the introduction of a system of obligatory language courses at all degree levels alongside a newly structured CEFR examination system. Simultaneously, the LC identified the core language courses and extras, which were designed in two categories: firstly, a nurturing instrument for talented and motivated students, secondly, a support instrument for disadvantaged students. To ensure a meaningful structure and proportionate assistance to these activities, standard classroom management techniques were complemented by carefully planned learning management systems (LMS) and ICT-associated learning (Moodle and Mahara environment, shared learning via video-conferences), which called for both technically and financially demanding course support. Besides the core courses, the LC provides optional courses and modules with a specific focus, where participants may be heterogeneous in terms of their learning statute (academic staff, undergraduate, postgraduate, etc.) to ensure also fruitful intergenerational and intellectually inspiring communication encounters. Among the courses, there are academic writing and argumentative writing courses, moderated discussions in German on socio-cultural phenomena, intercultural training, and presentation skills.

A completely new concept of a complementary course was introduced as "Language and Culture Scheme" accommodating the need of students for a direct exposure to the target language reality. This scheme is run in collaboration with three international partners (University of Central Lancashire, Preston, University of Leipzig, Germany, University of Alicante, Spain). Based on the four-year experience, the programme is seen as an authentic asset, attracting students both in higher numbers and of impressive study records. Their feedback on the programme, which generally involves a project work in international teams, company visits and follow-up assignments, common seminars and cultural presentations, and last but not least, peer socializing, was entirely positive. Among other benefits, the students got feedback on their communication style from peers, built their self-esteem and thus readiness to be heard, and extended their portfolios for the labour market.

\section{Conclusions}

All processes LCs employ to define and phrase their missions, as well as carry them forward within university settings are significantly individual with regard to the specific context of an institution and subject to careful consideration. An HEIs' debate on defining certain "universal elements" the institutions share and which might help to build cornerstones of their identities, has brought to attention also discrepancies and specificities of these HEIs. The soul-seeking processes have not been fully accommodated yet and the debates on the core missions are likely to continue. The same holds true also for the LCs most of them may build their strategies on the overall aims of their HEIs to strive for higher rankings, however, the particular practices they put in place depend largely on their roles within the institutions - whether they are seen more as mere service units or emancipated integral parts of the whole HEI. Depending on how successful LCs are in this self-identification processes within their HEIs, their voice will be heard in strive to constitute meaningful LC fundamentals and path towards them. The crucial element of the process is collaborative communication.

Inspiration taken from the marketing interdisciplinary approach to formulating educational aims and identities of LCs enables them to see their own objectives by a perspective of other disciplines (as well as respective academics) and find niches where a common work may be executed. This approach, to a degree, offers a potential to sound less "aggressive", and vice versa, more cooperative and persuasive in terms of formulating language policies within universities. Contributing to accomplishments of all-university goals may help the LCs identify their work more concretely and become inherent members of all activities that comprise of communicating scientific results. A part of earlier used job descriptions of LCs language teachers may be revised to set new concepts of LCs' participation in generating and transferring academic results. Categories of the THE World University Ranking provide a thorough overview where space for stepping out of the comfort classroom teaching zone for LCs may be found, as well as some of the examples, given in 2.2.

To point out indicators worth further examining, the LCs may see collaboration opportunities with faculty scholars, perhaps surprisingly, however, mainly in the research and citation categories as well as in the category of the international outlook, to use the terminology of the THE World University Ranking. The choices though will be 
leveraged by qualification structures and capacities of the LCs, as well as by the access to funding. It is, on the one hand, certainly a challenging situation, on the other a typical opportunity to really conceptualize tertiary level language teaching as broader rhetoric training, intertwined with professional contexts in an intercultural academic setting and allowing the cultivation of the communication as such. Under the conditions of unceasingly developing vibrant and unpredictable $\mathrm{R} \alpha \mathrm{D}$ environments, the proposed approach offers a stable counterbalance and an opportunity to encompass the classical desire "to educate a whole person".

\section{REFERENCES}

[1] Aub-Buscher, G. \& Bickerton, D. "CercleS: The first decade 1991-2000.” M. Ruane, G., 2002

[2] Bologna Declaration of 19 June 1999, Joint declaration of the European Ministers of Education, Bologna 1999

[3] ENQA (European Association for Quality Assurance in Higher Education)

[4] European Higher Education Area Declaration, Vienna 2010

[5] Europeans and their languages. Special Eurobarometer 386, (EB77.1) http://ec.europa.eu/public_opinion/archives/ebs/ebs_386_en. pdf, 2012

[6] Firth, A.: The lingua franca factor. Intercultural pragmatics 6.2, $147-170,2009$

[7] Guidelines for Quality Assurance in the European Higher Education Area. ENQA: Helsinki 2005.

[8] Horizon 2020, EC, https://ec.europa.eu/programmes/horizon2 020/en/what-horizon-2020, 2014

[9] House, J.: Subjectivity in English as Lingua Franca discourse: the case of "you know", Intercultural Pragmatics, 2009

[10] Jenkins, J.; Cogo, A.; Dewey, M.: Review of developments in research into English as a lingua franca; Language Teaching, 44.3.; pp. 281 -315; doi: 10.1017/S0261444811000115, 2011
[11] Kaur, J.: Pre-empting problems of understanding in English as a lingua franca, 2009

[12] Koblizkova, A.: Intercultural Communication through International English. In European ideas in the works of famous educationalist; internationalization, globalization and their impact on education. $101-115,2013$

[13] Kotler, P.: Marketing insights from A to Z, 2003

[14] Lichtkoppler, J.: "Male. Male." - "Male? The sex is male. The role of repetition in English as a lingua franca conversations." Vienna Working English Papers 16.1, 39 - 65, 2007

[15] Mauranen, A.: Signalling and preventing misunderstanding in ELF communication. International Journal of the Sociology of Language 177, 123 -150, 2006

[16] Pitzl, M-L.: "We should not wake up any dogs". Idiom and metaphorin ELF. In Mauranen \& Ranta (eds). 298 - 322, 2009

[17] Poljakovič, I.: Challenges and Aspirations of University Language Centres with Particular reference to Croatia. APPLES - Journal of Applied Language Studies 5 (2). 37 44, 2011

[18] Rontu, H.; Tuomi, U-K.: The role of research in teaching-oriented institutions: A case study of university language centres in Finland, 3 (2): 339 -354; doi 10.1515/cercles -2013-0018, 2013

[19] Rontu, H.; Tuomi, U-K.: Language centre teachers as researchers: The case of Finland 5(2):435 -480; doi 10.1515/cercles -2015-0022, 2015

[20] Santhiram, R.R., Tan, Y.S.: Globalization and Educational Language Policy in Malaysia: The Re-emergence of English as a Medium of Instruction and Its Impact on the Nation Building Process. In European ideas in the works of famous educationalist; internationalization, globalization and their impact on education. $61-89,2013$

[21] Seidlehofer, B.: Accommodation and the idiom principle in English as a Lingua Franca. Intercultural Pragmatics 6.2, 195 $-215,2009$

[22] Teichler, U.: Internationalisation of Higher Education: European Experiences, Asia Pacific Education Review, 2009

[23] Times Higher Education World University Ranking, https:/www.timeshighereducation.com/world-university-ran kings/2014/reputation-ranking\#!/page/0/length/25, 2014 